Computatio: Journal of Computer Science and Information Systems, 2/2 (2018), 196-195

\title{
IMPLEMENTASI PAPAN INFORMASI DIGITAL MENGGUNAKAN RASPBERRY PI 3 PADA STIPER SRIWIGAMA PALEMBANG
}

\author{
Rahmat Novrianda D ${ }^{1}$, R. M. Nasrul Halim ${ }^{2}$ \\ ${ }^{1}$ Program Studi Teknik Komputer, Fakultas Vokasi, Universitas Bina Darma \\ Jalan Jenderal A. Yani No. 3, Palembang, Indonesia \\ ${ }^{2}$ Program Studi Teknik Informatika, Fakultas Ilmu Komputer, Universitas Bina Darma \\ Jalan Jenderal A. Yani No. 3, Palembang, Indonesia \\ E-mail: ${ }^{1}$ rahmat.novrianda.d@gmail.com, ${ }^{2}$ nasrul.halim@binadarma.ac.id
}

\begin{abstract}
Abstrak
STIPER Sriwigama Palembang merupakan salah satu sekolah tinggi ilmu pertanian yang terdapat di Kota Palembang. Sama halnya dengan perguruan tinggi lainnya, dalam lingkungan STIPER Sriwigama Palembang terdapat dosen, staf dan mahasiswa. STIPER Sriwigama Palembang dalam menginformasikan tentang kehadiran dosen saat ini masih menggunakan papan informasi manual sederhana untuk menampilkan nama-nama dosen yang hadir atau tidak dengan tampilan yang statis, tidak menarik dan tidak akurat. Tujuan penelitian ini adalah untuk membangun suatu papan informasi digital yang dinamis dimana informasi didalamnya dapat diatur sesuai dengan kebutuhan, yang dapat dikelola oleh bagian informasi. Penelitian ini menggunakan Raspberry Pi yang akan menghubungkanTV LED dengan komputer bagian informasi. Penelitian ini akan menghasilkan papan informasi yang berisi fitur-fitur yang menarik seperti penggunaan gambar dan teks berjalan dan memberikan informasi tentang kehadiran dosen sedang mengajar ataupun sedang tidak mengajar yang dapat diatur melalui komputer bagian informasi. Dikarenakan masih dalam proses penelitian, maka keluaran saat ini akan dijelaskan terbatas pada desain tampilan serta juga dijelaskan tentang konfigurasi Raspberry Pi 3 model B sehingga dapat memodifikasi TV LED menjadi papan informasi digital.
\end{abstract}

Kata kunci-Dosen, Informasi Digital, Raspberry Pi, TV LED

\begin{abstract}
STIPER Sriwigama Palembang is one of the high school agricultural sciences located in the city of Palembang. As with other universities, in the STIPER Sriwigama Palembang environment there are lecturers, staff and students. STIPER Sriwigama Palembang in informing about the presence of lecturers is currently still using a simple manual information board to display the names of lecturers present or not with a static, unattractive and inaccurate display. The purpose of this research is to build a dynamic digital information board where information in it can be arranged according to needs, which can be managed by the information section. This research uses Raspberry Pi which will connect the LED TV with the computer part information. This research will produce an information board that contains interesting features such as the use of running images and text and provide information about the presence of lecturers who are teaching or not teaching which can be arranged through the computer information section. Because it is still in the research process, the current output will be explained limited to the display design and also explained about the configuration of the Raspberry Pi 3 model B so that it can modify the LED TV into a digital information board.
\end{abstract}

Keywords - Lecturer, Digital Information, Raspberry Pi, LED TV 


\section{PENDAHULUAN}

STIPER Sriwigama Palembang yang merupakan salah satu perguruan tinggi ilmu pertanian dan kehutanan yang berada di Kota Palembang [1], saat ini memiliki papan informasi untuk kehadiran dosen dengan menggunakan bentuk papan mading dengan ditulis tangan menggunakan spidol ataupun dengan menempelkan kertas pemberitahuan. Dimana informasi merupakan data yang telah diolah menjadi bentuk yang lebih berguna bagi yang menerima [2]. Oleh karena itu, sebagai salah satu perguruan tinggi, STIPER Sriwigama Palembang seharusnya meningkatkan media penampil informasi khususnya informasi kehadiran dosen. Salah satu hal yang dapat dikembangkan sejalan dengan perkembangan teknologi adalah merancang papan informasi digital yang memanfaatkan TV LCD yang terhubung dengan Raspberry Pi 3. Raspberry Pi 3 (juga dikenal sebagai RasPi) adalah sebuah SBC (Single Board Computer) seukuran kartu kredit yang dikembangkan oleh Yayasan Raspberry Pi di Inggris (UK) [3]. Spesifikasi teknis Raspberry Pi terdiri atas: Prosesor Broadcom BCM2835 700MHz, memori $512 \mathrm{MB}$ untuk Tipe B atau 256MB untuk tipe A, memakai SD Card sebagai pengganti hardisk dan memakai daya $2,5 \mathrm{~W}$ serta berdimensi 3,37" x 2,21" x 0,83 " dan memiliki berat $45 \mathrm{gr}$ [4]. Komputer kecil ini bisa digunakan untuk proyek-proyek elektronik dan hal lainnya yang bisa dilakukan oleh desktop komputer seperti sebagai mesin pengolah kata, games dan perangkat ini juga mampu memainkan video beresolusi tinggi [5]. Layaknya sebuah PC, Raspberry Pi membutuhkan Operating System (OS) agar dapat digunakan. OS ini disimpan dalam Secure Digital (SD) Card yang digunakan juga untuk media penyimpanan data seperti halnya hardisk [6]. Oleh karena itu, pada penelitian ini digunakanlah OS Raspbian untuk menjalankan Raspberry Pi 3.

Pada penelitian ini akan dibahas tentang cara pemasangan OS Raspbian pada Raspberry Pi 3, pemasangan perangkat Raspberry Pi pada TV LED hingga desain tampilan Informasi Digital yang akan tampil pada papan (TV LED). Untuk dapat menghubungkan antara TV LED dengan Raspberry Pi 3 tentunya TV LED harus memiliki port HDMI, sehingga dengan bantuan kabel HDMI yang digunakan untuk menghubungkan Raspberry Pi 3 ke TV LED dengan tampilan high definition [7]. Hal ini didukung juga dengan perangkat Raspberry Pi 3 yang memiliki port HDMI yang digunakan sebagai audio dan video output [8]. Setelah Raspberry Pi 3 dapat terhubung dengan TV LED, maka selajutnya adalah mengatur desain tampilan yang akan digunakan pada saat menampilkan informasi digital pada TV LED dan juga desain form kehadiran dosen yang dapat diakses melalui komputer bagian informasi. Desain tampilan yang akan dirancang adalah desain suatu aplikasi, dimana secara istilah aplikasi adalah program siap pakai yang direka untuk melaksanakan suatu fungsi bagi pengguna atau aplikasi yang lain dan dapat dipergunakan oleh sasaran yang dituju [9].

\section{METODE PENELITIAN}

\subsection{Metode Action Research}

Dalam pelaksanakan proses penelitian ini maka digunakan metode penelitian Action Research yang merupakan suatu metode dalam bentuk perancangan penelitian, di dalam metode penelitian action research, peneliti menggambarkan, menginterpretasi dan menjelaskan suatu situasi sosial pada waktu yang bersamaan dengan melakukan perubahan atau intervensi dengan tujuan perbaikan atau partisipasi [10]. Berikut adalah gambar dan penjelasan terhadap tahapan metode penelitian action research yang digunakan pada penelitian ini, yaitu : 
Computatio: Journal of Computer Science and Information Systems, volume 2, no. 2, Oktober 2018

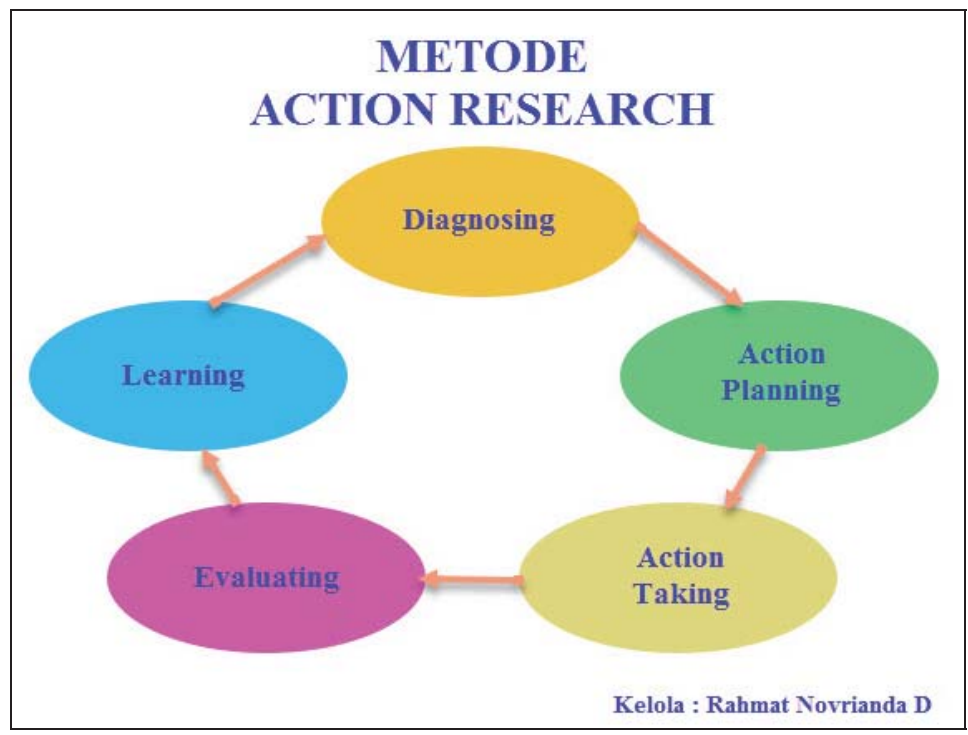

Gambar 1 Metode Action Research (Sumber : kelola sendiri)

\subsubsection{Melakukan diagnosa (diagnosing)}

Melakukan identifikasi masalah yang dialami oleh pihak STIPER Sriwigama Palembang berkaitan dengan pemanfaatan papan informasi khususnya kehadiran dosen dan staf pada ruangan dosen dan staf dengan cara observasi dan juga wawancara terhadap admin operator yang ada disana, serta dosen dan staf.

\subsubsection{Membuat rencana tindakan (action planning)}

Membuat suatu perencanaan yang dapat dilakukan untuk memberi solusi ataupun menyelesaikan permasalahan berkaitan dengan papan informasi khususnya untuk kehadiran dosen dan staf di lingkungan STIPER Sriwigama Palembang.

\subsubsection{Melakukan tindakan (action taking)}

Melakukan tindakan dengan mengembangkan teknologi saat ini untuk diterapkan pada papan informasi, dimana menggunakan perangkat Raspberry Pi 3 dan TV LED untuk mengembangkan papan informasi digital dengan tampilan yang jauh lebih baik dan menarik dibandingkan papan informasi yang digunakan STIPER Sriwigama Palembang saat ini.

\subsubsection{Melakukan evaluasi (evaluating)}

Setelah seluruh instalasi dan konfigurasi telah dilakukan, maka akan dilakukan evaluasi yang bertujuan untuk mengetahui kekurangan ataupun pengembangan yang dapat dilakukan terhadap papan informasi digital sesuai dengan perkembangan teknologi.

\subsubsection{Pembelajaran (learning)}

Tahapan ini merupakan tahapan akhir, dimana staf ataupun admin operator dapat melakukan pembelajaran terhadap penggunaan, pemeliharaan hingga pengembangan ataupun pembaharuan yang dapat dilakukan terhadap papan informasi digital yang diimplementasikan pada STIPER Sriwigama Palembang. 


\section{HASIL DAN PEMBAHASAN}

\subsection{Konfigurasi Raspberry Pi 3}

Pada penelitian ini, OS yang digunakan untuk Raspberry Pi 3 adalah OpenELEC Kodi. Proses instalasi OS ini tidak sama dengan cara instalasi OS pada komputer (PC) atau laptop. Hal ini disebabkan karena media penyimpanan yang digunakan pada Raspberry Pi 3 berupa SD card. Berikut konfigurasi yang dilakukan untuk pemasangan OS Raspbian pada Raspberry Pi 3:

$>$ Setelah SD Card di-format dan siap digunakan, maka proses selanjutnya adalah memindahkan OS OpenELEC Kodi ke dalam SD Card agar dapat digunakan pada Raspberry Pi 3.

> Masukkan SD Card ke dalam SD Card Reader, selanjutnya periksa Drive Letter pada windows explorer, misalnya SD Card anda di deteksi sebagai drive D:

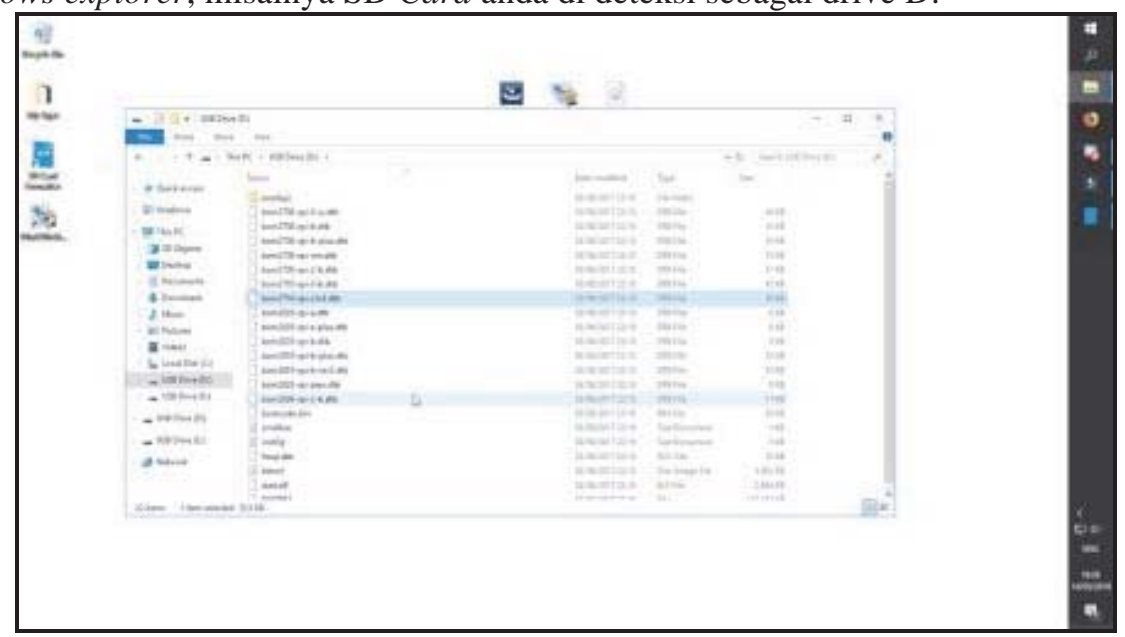

Gambar 2 SD Card Telah Terdeteksi di Komputer

Jalankan program Win32DiskImager dari menu desktop ataupun start menu.

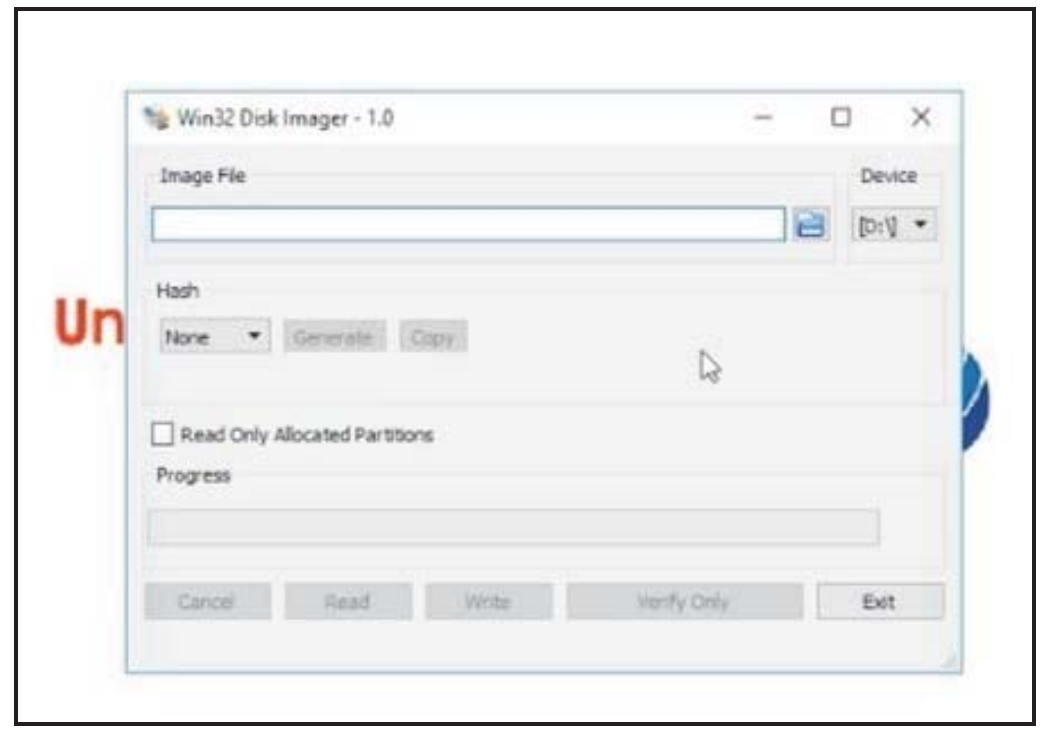

Gambar 3 Interface Aplikasi Win32 Disk Imager 
Computatio: Journal of Computer Science and Information Systems, volume 2, no. 2, Oktober 2018

$>$ Pilih file image OSMC yang telah di-download.

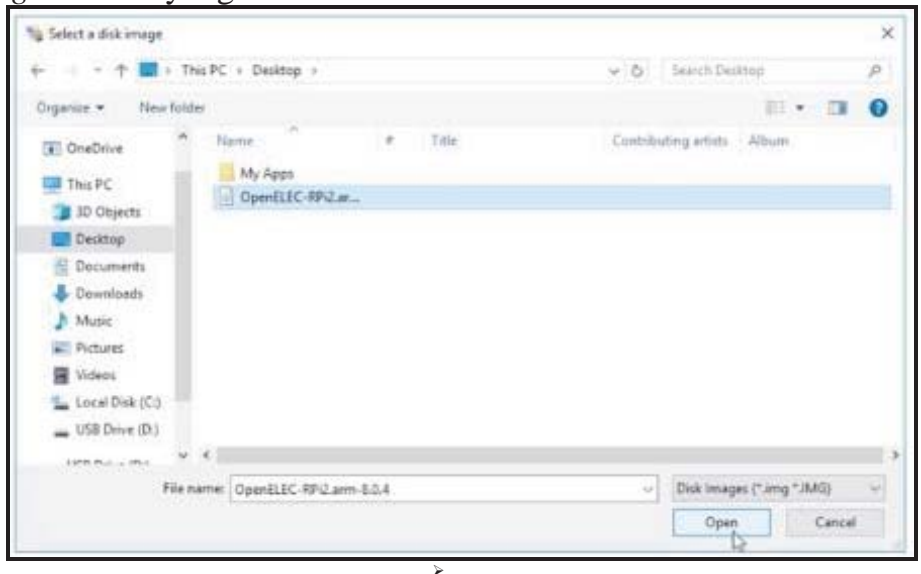

- Gambar 4 Browse file OS OpenELEC Kodi

- Pilih Drive Letter SD Card, dimana pada penelitian ini SD Card berada pada drive D:.

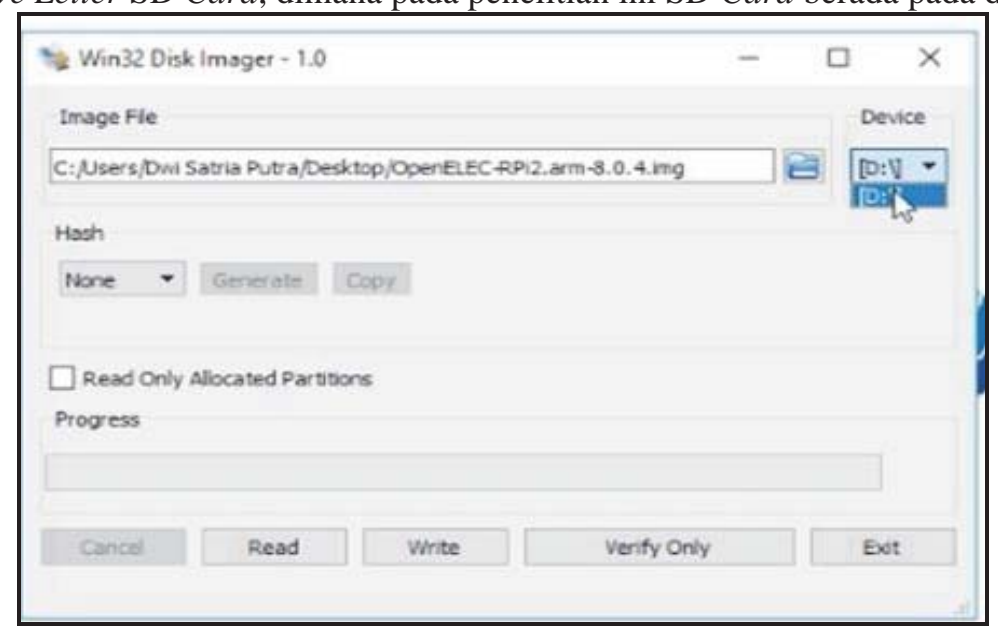

Gambar 5 Pemilihan Device SD Card

Agar proses pemindahan berjalan maka klik write dan tunggu sampai proses write complete

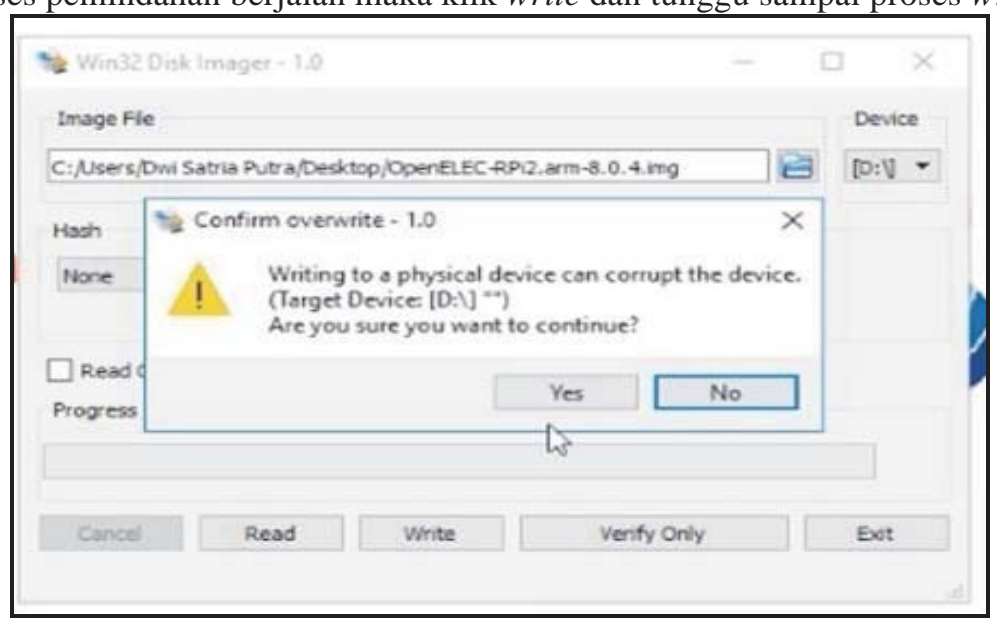

Gambar 6 Proses Write Data OS ke SD Card 
Setelah selesai, Exit program dan lepaskan SD Card

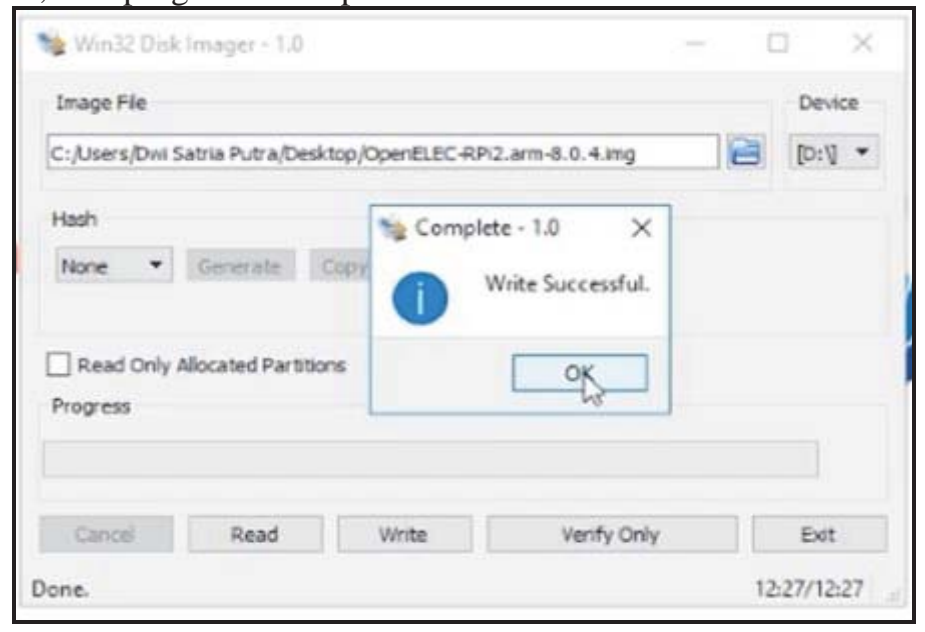

Gambar 7 Proses Write Data Selesai

Berikut ini adalah proses pemasangan SD card yang telah memiliki file ekstrak dari OS Raspbian pada perangkat Raspberry Pi 3:

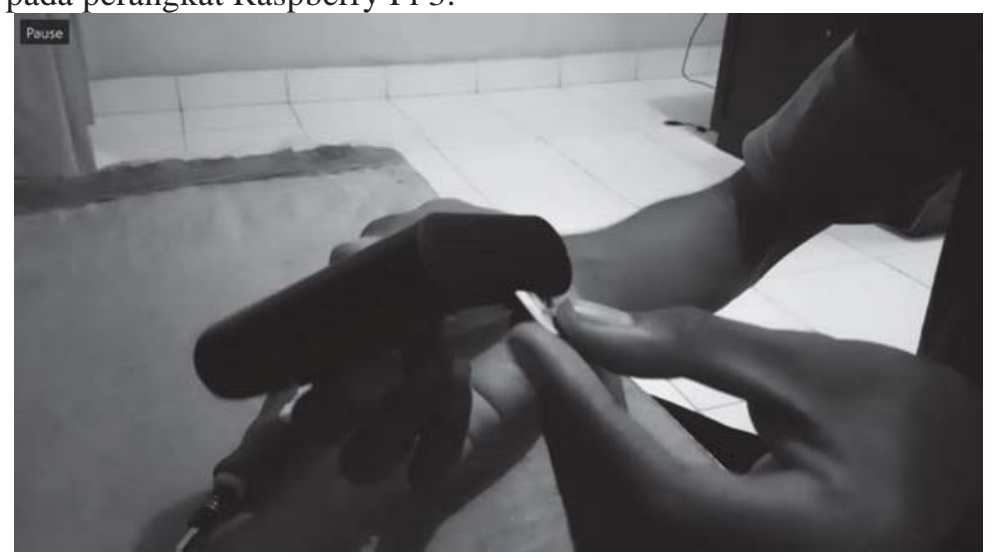

Gambar 8 Pemasangan SD Card pada Raspberry Pi 3

Pada gambar 9 di bawah ini terlihat proses pemasangan kabel power listrik Raspberry Pi 3 serta proses menghubungkan Raspberry Pi 3 ke TV LED dengan menggunakan kabel HDMI.

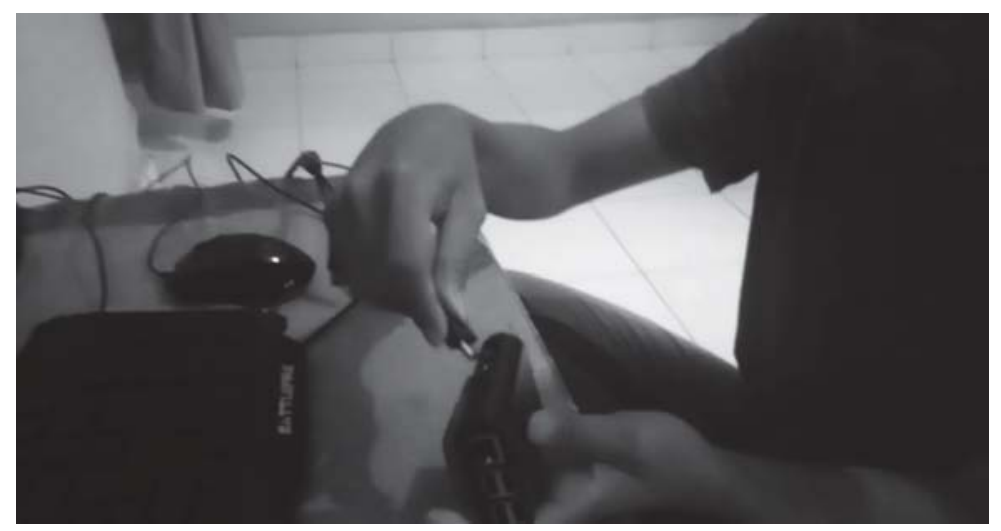

Gambar 9 Pemasangan kabel power listrik dan menghubungkan Raspberry Pi 3 ke TV LED 
Computatio: Journal of Computer Science and Information Systems, volume 2, no. 2, Oktober 2018

$>$ Berikut ini adalah proses mengaktifkan Raspberry Pi 3 dan otomatis Raspberry Pi 3 akan melakukan boot, terlihat pada gambar 10 .

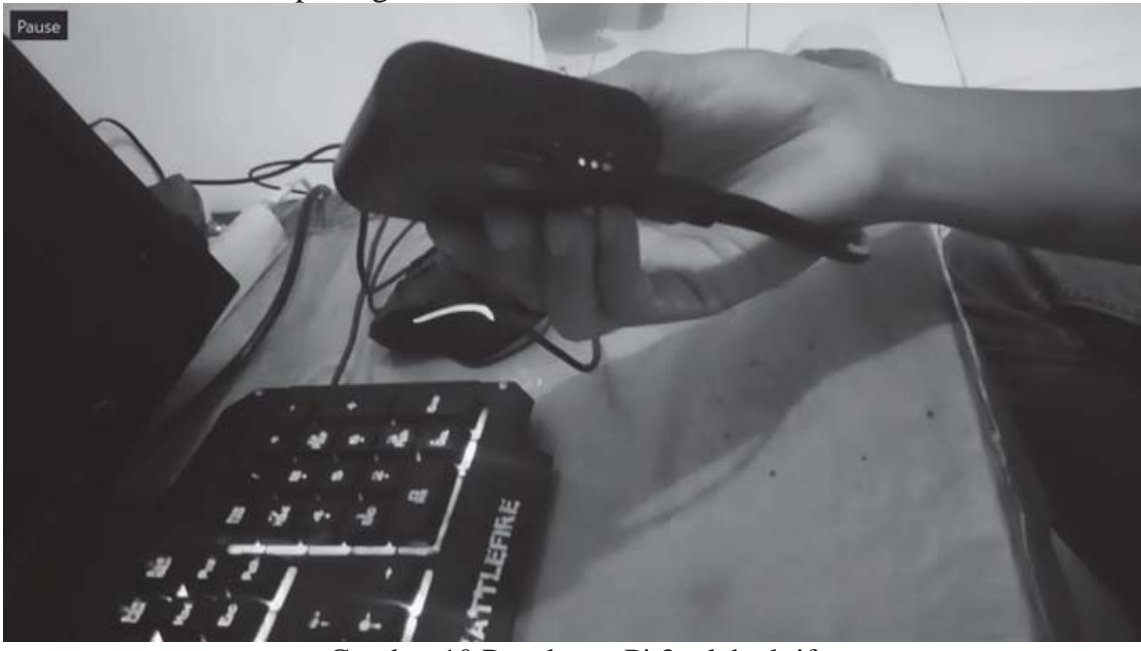

Gambar 10 Raspberry Pi 3 telah aktif

Tunggu sampai Raspberry sukses boot dari SD Card dan Proses Intall OS selesai.

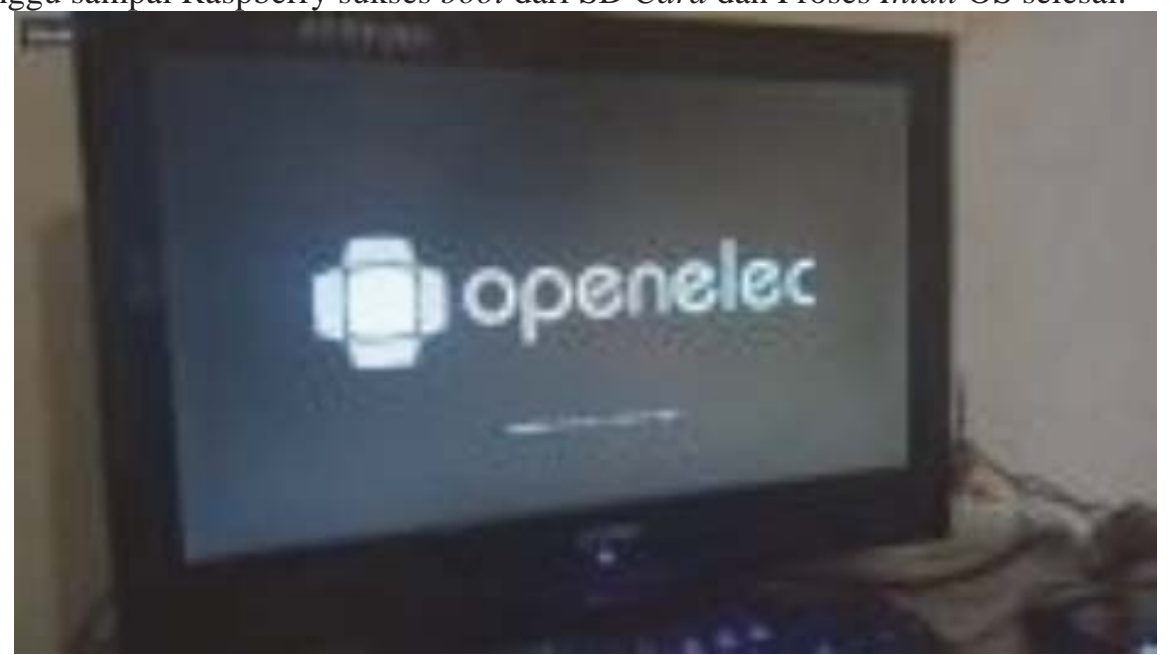

Gambar 11 Proses Installing OS

> Lakukan first time setup seperti memasukan jaringan Wi-fi kedalam Raspberry

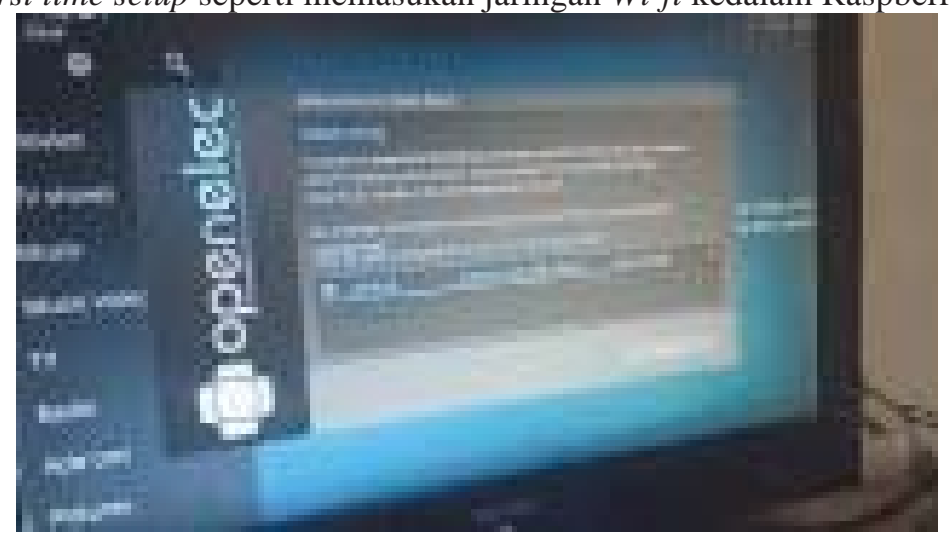

Gambar 12 Memasukan jaringan Wi-Fi 
$>$ Setelah selesai Proses installasi OS, perangkat akan restart otomatis.

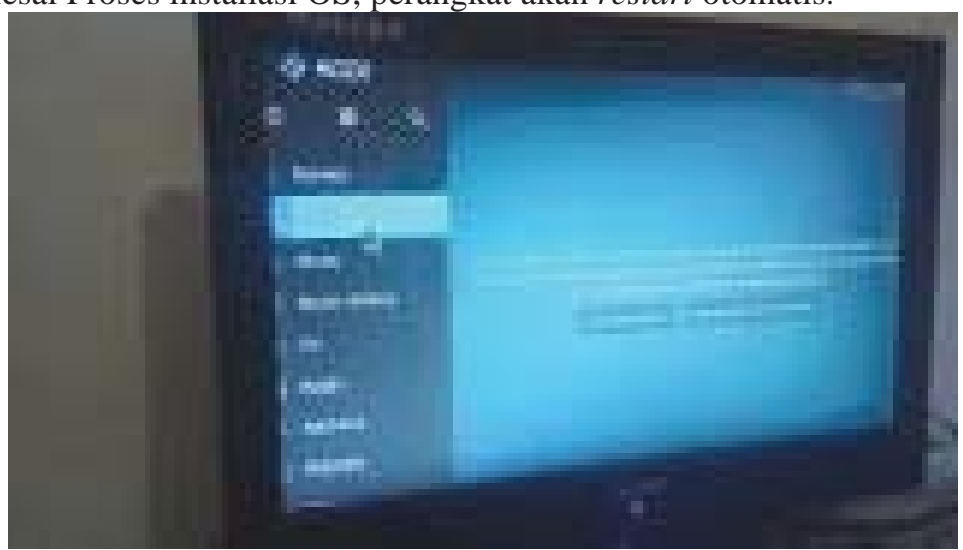

Gambar 13 Proses Installasi OS Selesai

3.2 User Interface pada PC admin operator dan papan informasi digital

Dari penelitian yang telah dilakukan, maka diperolehlah hasil dari tampilan ataupun user interface dari form login kehadiran dosen dan staf hingga user interface papan informasi digital yang akan tampil pada TV LED yang telah terhubung terhadap perangkat Raspberry Pi 3. Berikut ini adalah user interface yang telah dibangun:

$>$ Berikut ini adalah user interface form login dosen dan staf pada PC admin operator:

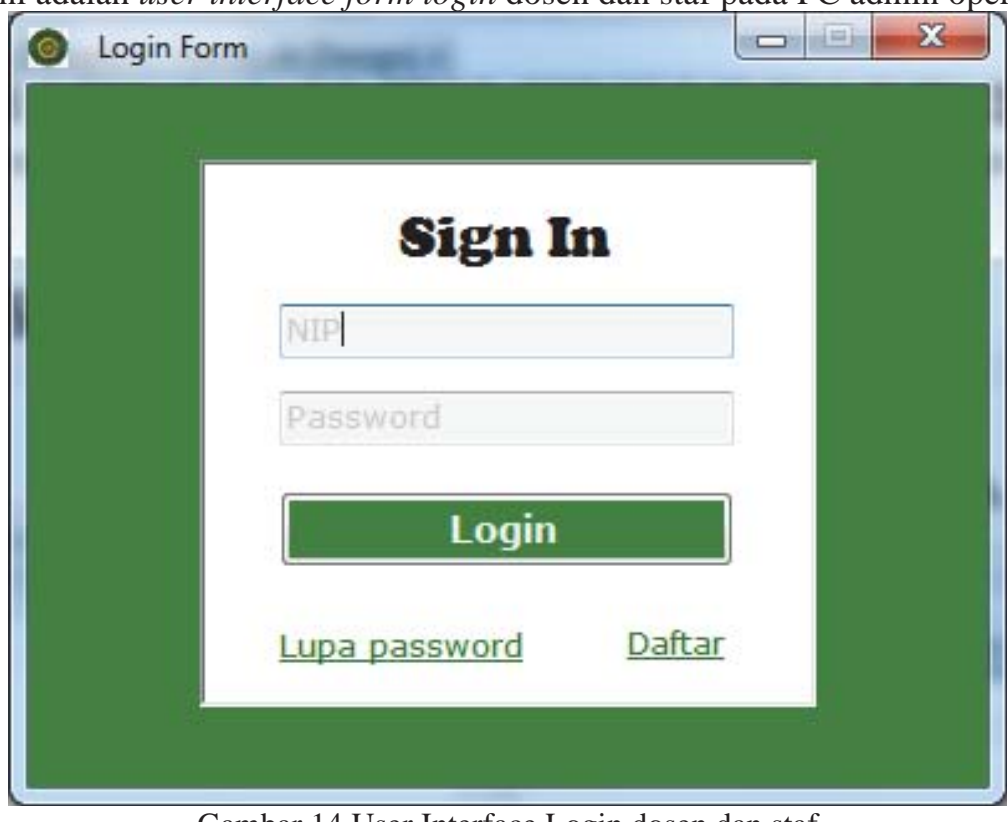

Gambar 14 User Interface Login dosen dan staf

Berikut ini merupakan form yang digunakan dalam mengisikan data lengkap dosen dan staf agar tersimpan ke dalam database PC admin operator dan dapat digunakan dalam melakukan absen masuk ataupun keluar dosen dan staf. 
Computatio: Journal of Computer Science and Information Systems, volume 2, no. 2, Oktober 2018

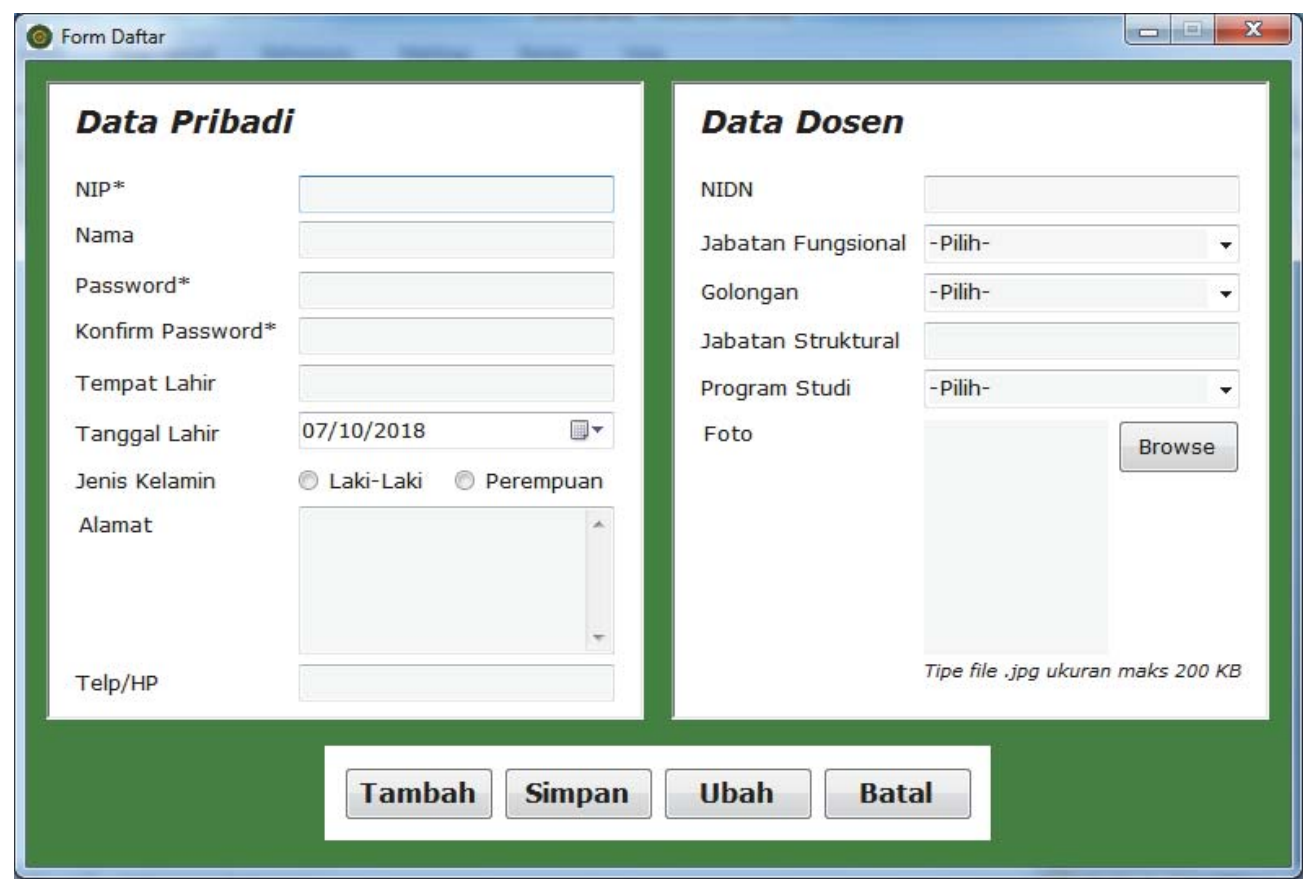

Gambar 15 User Interface Form Input dan Edit Data Dosen dan Staf

Pada gambar 16, terlihat user interface absen masuk dan absen keluar untuk dosen dan staf, dimana jika dosen atau karyawan telah melakukan absen masuk ataupun absen keluar maka akan tampil informasi pada papan informasi digital (TV LED yang telah terhubung dengan Raspberry Pi 3).

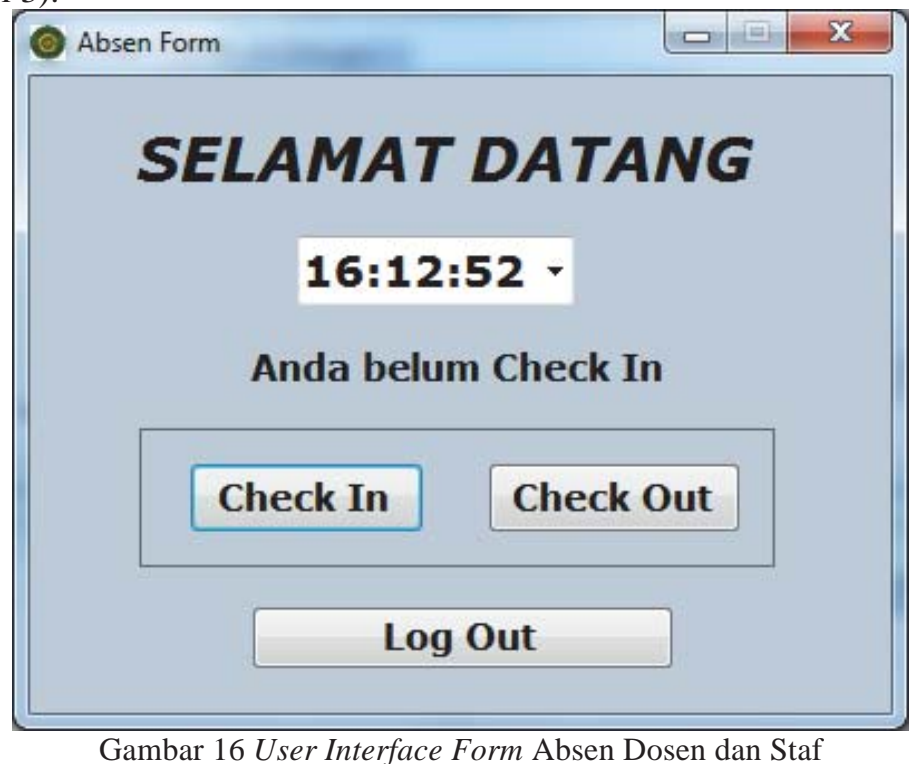

Pada gambar 17, terlihat user interface yang telah tampil pada papan informasi digital yang menggunakan media TV LED yang telah dihubungkan terhadap Raspberry Pi 3. 


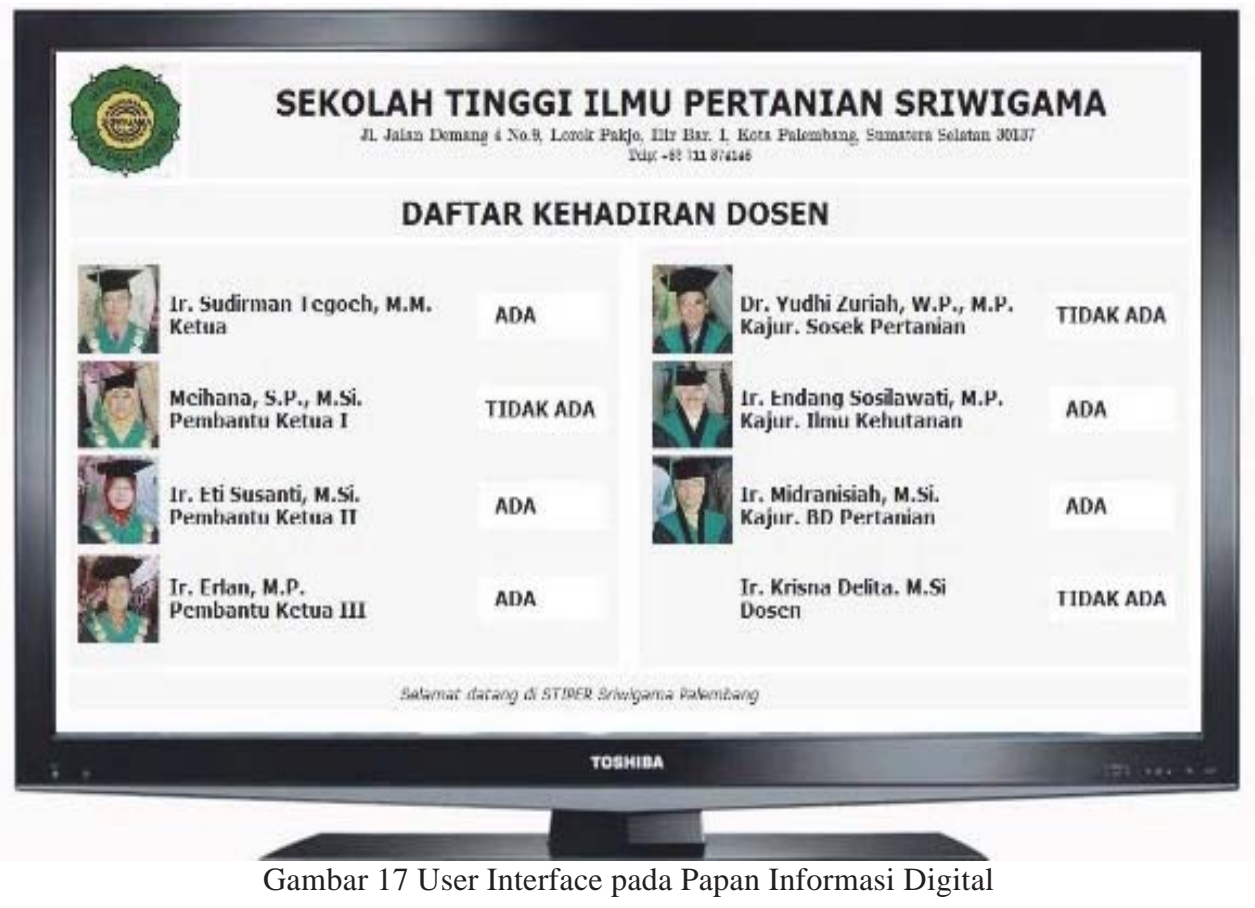

\section{KESIMPULAN}

Pada penelitian ini, tahapan penelitian yang telah dilakukan mulai dari diagnosing, action planning hingga action taking. Oleh karena itu, dilakukanlah beberapa konfigurasi terhadap Raspberry Pi 3 sehingga dapat dihubungkan terhadap TV LED dan memberikan perubahan menjadi smart TV. TV LED yang telah terhubung dengan Raspberry Pi 3 ini digunakan sebagai papan informasi digital yang dapat menampilkan informasi kehadiran dosen dan staf pada lingkungan STIPER Sriwigama Palembang khusunya di depan ruang dosen dan staf. Pada penelitian ini, dihasilkan juga form login dan absen dosen serta staf yang dapat digunakan oleh dosen dan staf sehingga dapat memberikan informasi ADA atau TIDAK ADA dosen dan staf pada lingungan STIPER Sriwigama Palembang. Hal ini memberikan nilai tambah dalam pengembangan teknologi pada STIPER Sriwigama Palembang, dimana tampilan papan informasi yang telah berbasis digital.

\section{UCAPAN TERIMA KASIH}

Terima kasih diucapkan kepada Ketua serta staf STIPER Sriwigama atas dukungan dan bantuannya, serta diucapkan juga terima kasih kepada mahasiswa yang telah membantu dalam pengumpulan data dan referensi berkaitan dengan penelitian yang dilakukan.

\section{DAFTAR PUSTAKA}

[1] Novrianda R. Rancang Bangun Keamanan Jaringan Wireless Pada Stiper Sriwigama Palembang Dengan Radius Server. Jurnal Maklumatika. 2017 Jul;4(1).

[2] Sihotang HT. Sistem Informasi Pengagendaan Surat Berbasis Web Pada Pengadilan Tinggi Medan. Journal Of Informatic Pelita Nusantara. 2018 Feb 16;3(1).

[3] Panuntun R, Rochim AF, Martono KT. Perancangan Papan Informasi Digital Berbasis Web pada Raspberry pi. Jurnal Teknologi dan Sistem Komputer. 2015 Apr 20;3(2):192-7. 
Computatio: Journal of Computer Science and Information Systems, volume 2, no. 2, Oktober 2018

[4] Dawood R, Qiana SF, Muchallil S. Kelayakan Raspberry Pi sebagai Web Server: Perbandingan Kinerja Nginx, Apache, dan Lighttpd pada Platform Raspberry Pi. Jurnal Rekayasa Elektrika. 2014 Apr 30;11(1):25-9.

[5] Sudarto F, Purwandari E, Andrea AS. Pengangkat Barang Pada Kondisi Banjir Berbasis Raspberry Pi Melalui Twitter Sebagai Output Media Informasi. CERITA Journal. 2015;1(1):74-85.

[6] Prabowo IP, Nugroho S, Utomo D. Penggunaan Raspberry Pi sebagai Web Server pada Rumah untuk Sistem Pengendali Lampu Jarak Jauh dan Pemantauan Suhu.

[7] Ladita W, Pradana HA. Konfigurasi Smart TV Menggunakan Raspberry Pi Berbasis Linux Debian. Jurnal Sisfokom (Sistem Informasi dan Komputer). 2015 Mar 30;4(1):3440.

[8] Hasanudin M. Rancang Bangun Sistem Pembelajaran Secure Interactive Dengan Learning Management System Berbasis Raspberry Pi. Konferensi Nasional Sistem Informasi (KNSI) 2018. 2018 Mar 8.

[9] Sianturi FA. Perancangan aplikasi pengamanan data dengan kriptografi Advanced Encryption Standard (AES). Pelita Informatika: Informasi dan Informatika. 2013 Aug $18 ; 4(1)$.

[10] Ardiyasa, I. W. (2015). Pemanfaatan Raspberry PI dan Webcam Untuk Layanan Monitoring Ruangan Berbasis Web. Proceedings Konferensi Nasional Sistem dan Informatika (KNS\&I). 